\title{
Compositional aspects of the vapour-phase epitaxial growth of GaInAs layers from $\mathbf{G a}-\mathbf{I n}-\mathbf{A s}-\mathbf{H}-\mathbf{C l}$ system
}

\author{
V N MANI \\ Crystal Growth Centre, Anna University, Madras 600025, India \\ Present Address: Centre for Materials for Electronics Technology (C-MET), A.P.E.L. \\ Building, Kushaiguda, E.C.I.L. (PO), Hyderabad 500 762, India \\ MS received 13 April 1994; revised 1 August 1994

\begin{abstract}
Following physicochemical analysis, a kinetic model is described with a scheme of reactions in order to predict the growth rate and the compositional aspects of the ternary epitaxial layers $\mathrm{Ga}_{x} \mathrm{In}_{1-x}$ As grown from $\mathrm{Ga}-\mathrm{In}-\mathrm{As}-\mathrm{Cl}-\mathrm{H}$ vapour phase. Theoretical expressions for the deposition rate have been derived in terms of experimental growth parameters and the relationship between growth kinetics and compositional aspects is investigated. Good agreement is obtained between the layer composition calculated based on the proposed model and the experimental values reported in the literature.
\end{abstract}

Keywords. Vapour-phase epitaxy; surface coverage; growth kinetics; lattice match.

\section{Introduction}

The evolution of vapour-phase epitaxial (VPE) growth technology has led to advanced multilayer structures of ternary and quaternary III-V materials and devices. The ternary and quaternary alloys of $\mathrm{AlGaAs}$, GaInAs, GaInAsP, etc. are promising materials for optoelectronic applications (Olsen and Zamerowski 1979; Olsen 1982; Bachem and Heyen 1984). For most of the devices, as exact as possible a lattice match between epitaxial layer and substrate is a necessary condition for good device performance. Variation in layer composition will cause lattice mismatch. Moreover the requirement of composition uniformity is a particularly stringent one in the case of multiple-alloy heteroepitaxial structures such as $\mathrm{Ga}_{x} \operatorname{In}_{1-x} \mathrm{As}_{1-y} \mathrm{P}_{y} / \mathrm{InP}$, where the lattice parameters depend strongly on mole fractions $x$ and $y$. The experimentalist's main concern has been to have a model which relates the growth kinetics of the film with the experimental parameters like partial pressures and the deposition temperature. The aim of this paper is to obtain chemical engineering information regarding the growth kinetics and compositional variation aspects from the modelling of VPE ternary GaInAs system. It is possible to understand the growth process, to determine the optimum growth conditions, and to suggest a possible reaction mechanism that controls the growth.

Theoretical investigations of the composition control based on a pure thermodynamic approach to the $\mathrm{Ga}-\mathrm{In}-\mathrm{As}-\mathrm{Cl}-\mathrm{H}$ system have been performed by several workers (Nagai 1979; Chatterjee et al 1982; Jacobs et al 1984; Quinlan 1987; Lassala et al 1988).

In this paper, an attempt has been made to develop a model incorporating both thermodynamics and kinetics where the growth rate expression can be used to analyse the composition of the $\mathrm{Ga}_{x} \mathrm{In}_{1-x}$ As layer. 


\section{Thermodynamic analysis}

The overall process of deposition of $\mathrm{Ga}_{x} \mathrm{In}_{1-x}$ As on substrate surface from the vapour molecules of $\mathrm{GaCl}, \mathrm{InCl}$ and arsenic in the presence of hydrogen can be written as

$$
\begin{aligned}
& x \mathrm{GaCl}(\mathrm{g})+(1-x) \operatorname{InCl}(\mathrm{g})+1 / 4 \mathrm{As}_{4}(\mathrm{~g})+1 / 2 \mathrm{H}_{2}(\mathrm{~g}) \\
& \stackrel{\kappa}{\rightleftharpoons} \mathrm{Ga}_{x} \operatorname{In}_{1-x} \mathrm{As}(\mathrm{s})+\mathrm{HCl}(\mathrm{g}),
\end{aligned}
$$

where $x$ varies from 0 to 1 . The equilibrium constant $K$ can be given by

$$
K=\frac{a_{\mathrm{Ga}(x) \ln (1-x) \mathrm{As}} P_{\mathrm{HCl}}}{P_{\mathrm{GaCl}}^{x} P_{\operatorname{lnCl}}^{1-x} P_{\mathrm{As} 4}^{1 / 4} P_{\mathrm{Hz}_{2}}^{1 / 2}}
$$

where $a$ is the activity and the $P$ s are the partial pressures. The separate kinetic steps involved in the growth processes of GaInAs will be considered as adsorption processes based on models (Cadoret and Cadoret 1975; Chernov and Rusaikin 1978; Korec and Heyen 1982; Hong and Lee 1985; Nshizawa et al 1986; Mani et al 1987, 1988, $1990,1991)$. Thermodynamics does not provide a complete description of a growing system. It would require a detailed knowledge of the surface reaction mechanisms. Worthwhile information regarding the growth kinetics and composition of the deposited layer may be obtained by investigating the reaction scheme and treating the surface kinetics. Following the thermodynamic approach, a method for determining the composition has been presented. It follows with a reaction scheme as dissociation of $\mathrm{As}_{4}$ into $\mathrm{As}_{2}$, adsorption of $\mathrm{GaCl}$ and $\mathrm{InCl}$ molecules and surface reaction between $\mathrm{As}^{*}, \mathrm{GaCl}$ and $\mathrm{InCl}$ to form complex molecules $\mathrm{AsGaCl}$ ( and $\mathrm{AsInCl}^{*}$ respectively (*denotes the atoms or molecules in the adsorbed state). It will be assumed that the $\mathrm{GaAs}$ and InAs are formed at the surface by the reaction of adsorbed $\mathrm{AsGaCl}$ and AsInCl complexes with $\mathrm{H}_{2}$. It is also assumed that $\mathrm{Ga}_{x} \operatorname{In}_{1-x} \mathrm{As}$ is formed from the respective binaries $\mathrm{GaAs}$ and InAs and the $\mathrm{Ga}_{x} \operatorname{In}_{1-x}$ As molecule is incorporated into the lattice site. The following sequence of steps is taken into account:

(i) The dissociation reaction in the gaseous phase

$$
1 / 4 \mathrm{As}_{4}(\mathrm{~g}) \stackrel{\mathrm{K}_{1}}{\rightleftharpoons} 1 / 2 \mathrm{As}_{2}(\mathrm{~g})
$$

The equilibrium constant is given by

$$
\ln K_{1}=6 \cdot 2510-\frac{6849}{T}-0.257 \ln T .
$$

(ii) Adsorption of As on a free surface site

$$
1 / 2 \mathrm{As}_{2}+* \stackrel{\mathrm{K}_{2}}{\rightleftharpoons} \mathrm{As}^{*}
$$

where * denotes a site on the surface. The equilibrium constant is given by

$$
\ln K_{2}=-23 \cdot 4092+5 / 4 \ln T+16474 \cdot 385 / T \text {. }
$$


(iii) Adsorption of $\mathrm{GaCl}$ on a free site

$$
\mathrm{GaCl}+* \stackrel{\kappa_{3}}{\rightleftharpoons} \mathrm{GaCl}^{*}
$$

The value of $K_{3}$ is

$$
\ln K_{3}=-30 \cdot 9716+3 / 2 \ln T+25843 \cdot 5906 / T \text {. }
$$

(iv) Adsorption of $\mathrm{InCl}$ on a free site

$$
\begin{aligned}
& \mathrm{InCl}(\mathrm{g})+* \stackrel{\mathrm{K}_{4}}{\rightleftharpoons} \mathrm{InCl} * \\
& \ln K_{4}=-31 \cdot 3979+3 / 2 \ln T+23700 \cdot 879 / T .
\end{aligned}
$$

(v) The surface reaction of $\mathrm{As}^{*}$ and $\mathrm{GaCl}$ for the formation of a complex molecule AsGaCl*

$$
\mathrm{As}^{*}+\mathrm{GaCl} \stackrel{\boldsymbol{K}_{\mathbf{s}}}{\rightleftharpoons} \mathrm{AsGaCl}^{*}
$$

The reaction constant $K_{5}$ has been determined from the activities of the constituents as (Korec and Heyen 1982)

$$
\ln K_{5}=-30 \cdot 4551+3 / 2 \ln T+25843 \cdot 59 / T \text {. }
$$

(vi) The surface reaction of $\mathrm{As}^{*}$ and $\mathrm{InCl}$ for formation of a complex molecule AsInCl*

$$
\mathrm{As}^{*}+\mathrm{InCl} \stackrel{\mathfrak{K}_{6}}{\rightleftharpoons} \mathrm{AsInCl}{ }^{*}
$$

The reaction constant $K_{6}$ has been determined from the activities of the constituients as

$$
\ln K_{6}=-30 \cdot 9926+3 / 2 \ln T+23700 \cdot 8790 / T \text {. }
$$

(vii) Formation of $\mathrm{GaAs}$ from the surface reactions between $\mathrm{AsGaCl}^{*}$ and $\mathrm{H}_{2}$

$$
\begin{aligned}
& \mathrm{AsGaCl}^{*}+\mathrm{H}_{2} \stackrel{\mathrm{K}_{7}}{\rightleftharpoons} \mathrm{GaAs}^{*}+\mathrm{HCl}+\mathrm{H}, \\
& \ln K_{7}=-30.4336+3 / 2 \ln T-1.367 \times 10^{5} / T .
\end{aligned}
$$

(viii) Formation of InAs from the surface reactions between $\mathrm{AsInCl}^{*}$ and $\mathrm{H}_{2}$

$$
\begin{aligned}
& \mathrm{AsInCl}^{*}+\mathrm{H}_{2} \stackrel{\mathrm{K}_{8}}{\rightleftharpoons} \operatorname{InAs} *+\mathrm{HCl}+\mathrm{H}, \\
& \ln K_{8}=-62 \cdot 5144+3 / 2 \ln T-2.5772 \times 10^{4} / T .
\end{aligned}
$$

(ix) Formation of $\mathrm{Ga}_{x} \operatorname{In}_{1-x}$ As from the respective binaries can be given by

$$
x \mathrm{GaAs}^{*}+(1-x) \operatorname{InAs} \stackrel{\stackrel{K_{9}}{\rightleftharpoons}}{\rightleftharpoons} \mathrm{Ga}_{x} \mathrm{In}_{1-x} \mathrm{As}^{*}
$$


(x) Incorporation of $\mathrm{Ga}_{x} \operatorname{In}_{1-x} A s(s)$ into the lattice site

$$
\mathrm{Ga}_{x} \operatorname{In}_{1-x} \mathrm{As}^{*} \rightleftharpoons \mathrm{Ga}_{x} \operatorname{In}_{1-x} \mathrm{As}(s)+* \text {. }
$$

\section{Deposition rate}

The growth rate $(R)$ of the ternary GaInAs may be expressed as the sum of deposition rates of binary components

$$
R_{\text {GalnAs }}=R_{\text {GaAs }}+R_{\text {InAs }} \text {. }
$$

The formation of the complex molecules $\mathrm{AsGaCl}$ and $\mathrm{AsInCl}$ on the substrate surface are considered to be rate-determining. Hence the growth rate can be written from (11) and (13) as

$$
\begin{aligned}
& R_{\mathrm{GaAs}}=K_{5}\left[\mathrm{As}^{*}\right][\mathrm{GaCl}], \\
& R_{\mathrm{InAs}}=K_{6}\left[\mathrm{As}^{*}\right][\mathrm{InCl}] .
\end{aligned}
$$

If $[*]$ is the concentration of vacant sites on the surface, the total number of sites is given by

$$
\begin{aligned}
N= & {[*]+\left[\mathrm{As}^{*}\right]+\left[\mathrm{GaCl}^{*}\right]+\left[\mathrm{InCl}^{*}\right]+\left[\mathrm{AsGaCl}^{*}\right]+\left[\mathrm{AsInCl}^{*}\right] } \\
& +\left[\mathrm{GaAs}^{*}\right]+\left[\operatorname{InAs}{ }^{*}\right]+\left[\mathrm{Ga}_{x} \operatorname{In}_{1-x} \mathrm{As}^{*}\right],
\end{aligned}
$$

where $\left[i^{*}\right]$ is the concentration of species $i$ occupied on surface sites $(i=\mathrm{As}, \mathrm{GaCl}$, $\mathrm{InCl}, \mathrm{AsGaCl}, \mathrm{AsInCl}$ ). The fractional surface coverages of $\mathrm{As}, \mathrm{GaCl}, \mathrm{InCl}, \mathrm{AsGaCl}$, $\mathrm{AsInCl}$ are given by

and

$$
\begin{aligned}
& \theta_{\mathrm{As}}=K_{2}^{\prime} P_{\mathrm{As}_{4}}^{1 / 4} \theta_{v}, \\
& \theta_{\mathrm{GaCl}}=K_{3} P_{\mathrm{GaCl}} \theta_{v}, \\
& \theta_{\mathrm{InCl}}=K_{4} P_{\mathrm{InCl}} \theta_{v}, \\
& \theta_{\mathrm{AsGaCl}}=K_{5} K_{2}^{\prime} P_{\mathrm{As} 4}^{1 / 4} P_{\mathrm{GaCl}} \theta_{v},
\end{aligned}
$$

where

$$
\theta_{\mathrm{AsInCl}}=K_{6} K_{2}^{\prime} P_{\mathrm{As} 4}^{1 / 4} P_{\mathrm{InCl}} \theta_{v} \text {, }
$$

$$
\begin{aligned}
\theta_{v}= & \left\{1+K_{2}^{\prime} P_{\mathrm{As} 4}^{1 / 4}+K_{3} P_{\mathrm{GaCl}}+K_{4} P_{\mathrm{InCl}}+K_{2}^{\prime} K_{5} P_{\mathrm{As} 4}^{1 / 4} P_{\mathrm{GaCl}}\right. \\
& +K_{2}^{\prime} K_{6} P_{\mathrm{As} 4}^{1 / 4} P_{\mathrm{InCl}}+K_{7} K_{2}^{\prime} K_{5} P_{\mathrm{As} 4}^{1 / 4} P_{\mathrm{GaCl}} P_{\mathrm{H}_{2}}^{1 / 2} P_{\mathrm{HCl}}^{-1} \\
& \left.+K_{8} K_{2}^{\prime} K_{6} P_{\mathrm{As} 4}^{1 / 4} P_{\mathrm{InCl}} P_{\mathrm{H}_{2}}^{1 / 2} P_{\mathrm{HCl}}^{-1}\right\}^{-1}
\end{aligned}
$$

and $K_{2}^{\prime}=K_{1} K_{2}$.

Expressions for the deposition rates of $\mathrm{GaAs}$ and InAs are obtained in terms of partial pressures and (22) and (23) can be written using (25) to (29):

$$
\begin{aligned}
R_{\mathrm{GaAs}} & =K_{2}^{\prime} K_{5} P_{\mathrm{As} 4}^{1 / 4} P_{\mathrm{GaCl}} \theta_{v} N, \\
R_{\mathrm{InAs}} & =K_{2}^{\prime} K_{6} P_{\mathrm{As} 4}^{1 / 4} P_{\mathrm{InCl}} \theta_{v} N,
\end{aligned}
$$

where $N$ is the number of sites per unit area of the substrate. 
The ratio of the deposition rate of the GaAs component to the total growth rate determines the $\mathrm{Ga}$ concentration of the grown layer:

$$
x=R_{\mathrm{GaAs}} / R_{\mathrm{GaInAs}} .
$$

The growth rate expressions contain experimental input variables.

\section{Results and discussion}

It was shown in $\S 2$ that the thermodynamic parameters which determine composition stability are (i) the input gas pressures, (ii) substrate temperature and (iii) equilibrium constants for the reaction steps (11) and (13). The composition of $\mathrm{Ga}_{x} \operatorname{In}_{1-x}$ As ternary at a fixed deposition temperature is determined by the ratio $P_{\mathrm{GaCl}} / P_{\mathrm{InCl}}$.

Figure 1 shows the effect of deposition temperature on the growth rate for given growth conditions. It can be seen from the figure that for a particular deposition

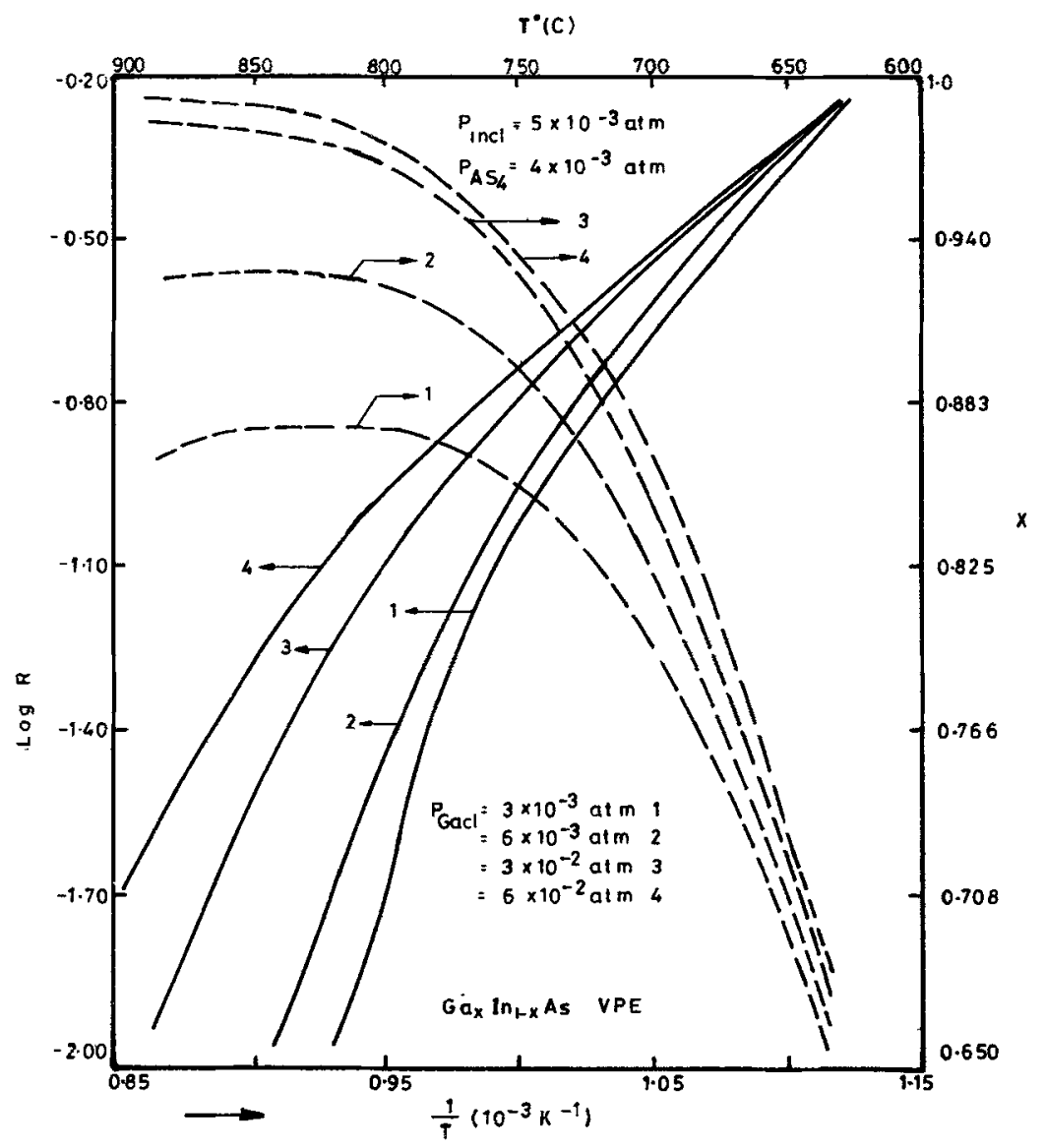

Figure 1. Deposition rate $R$ (- $\left(-\right.$ and mole fraction $x(--)$ of gallium in $\mathrm{Ga}_{x} \mathrm{In}_{1-x}$ As vs substrate temperature at fixed partial pressures of $\mathrm{InCl}$ and $\mathrm{As}_{4}$, and for various values of $P_{\mathrm{GaCj}}$. 
condition, the deposition rate of GaInAs increases as the partial pressure of $\mathrm{GaCl}$ increases. The change is composition is a consequence of the change in growth rate and is clear that as the growth rate increases the gallium content in the growing GaInAs layer decreases. This result suggests that in the GaInAs vapour phase epitaxial growth from $\mathrm{Ga}-\mathrm{In}-\mathrm{As}-\mathrm{H}-\mathrm{Cl}$ system composition is a function of growth rate. Experimental evidence for this theoretical view was also obtained by Chatterjee et al (1982). The relationship between growth rate and layer compositional variation is well reflected by the model, so that the concepts on which the model was developed appear to be justified. It is concluded that, in III-V ternary vapour-phase epitaxy, the growth kinetics plays an important role in controlling the layer composition.

The dependence of the growth rate on the $\mathrm{InCl}$ input partial pressure $\left(P_{\mathrm{InCl}}\right)$ as a function of deposition temperature is shown in figure 2 . The gallium mole fraction in the $\mathrm{Ga}_{x} \mathrm{In}_{1-x}$ As layer first increases with rising temperature and attains saturation which

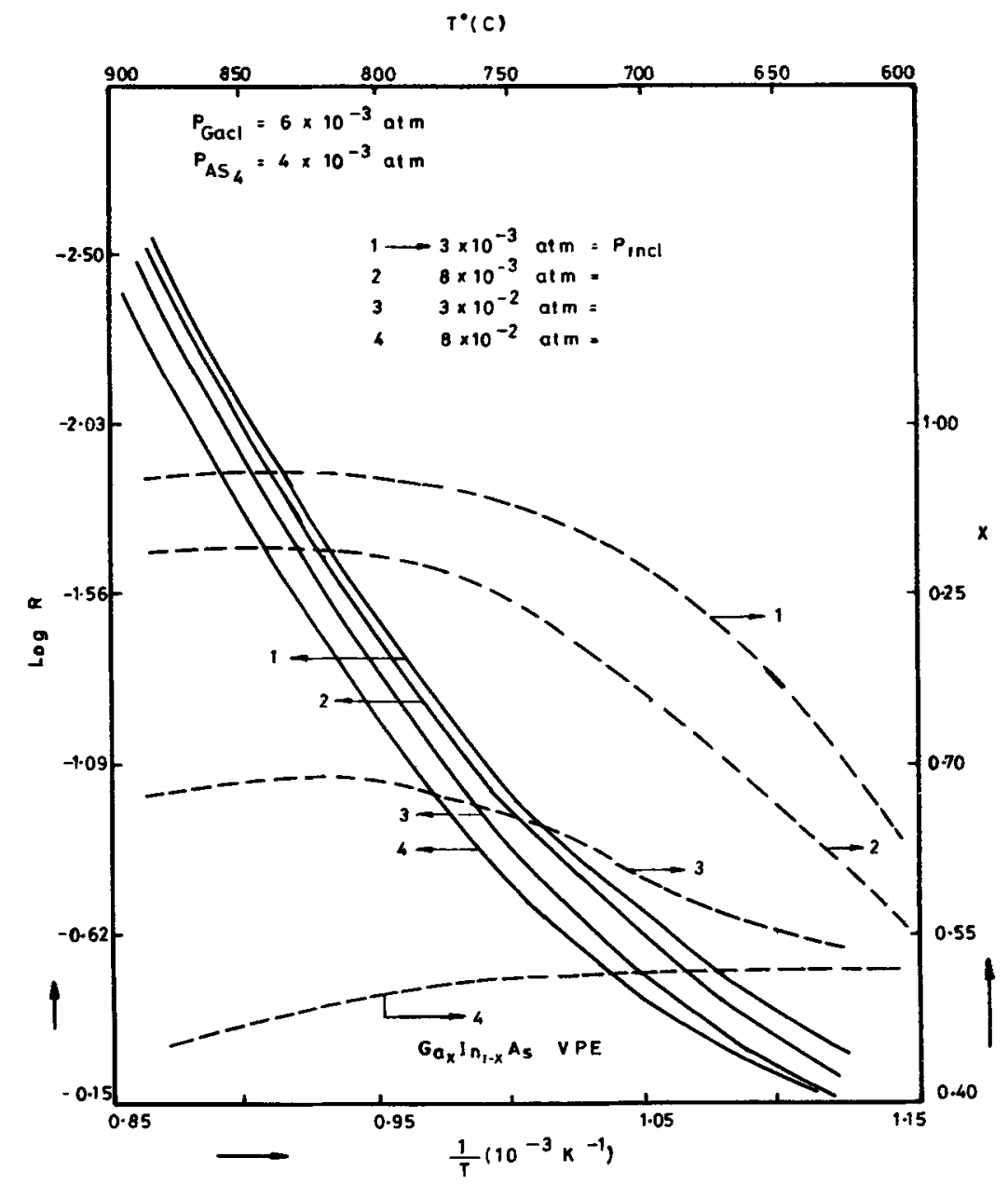

Figure 2. Deposition rate $R(-)$ and mole fraction $x(--)$ of gallium in GaInAs vs substrate temperature at fixed partial pressures of $\mathrm{GaCl}$ and $\mathrm{As}_{4}$ and for various values of $\boldsymbol{P}_{\text {Incl }}$. 


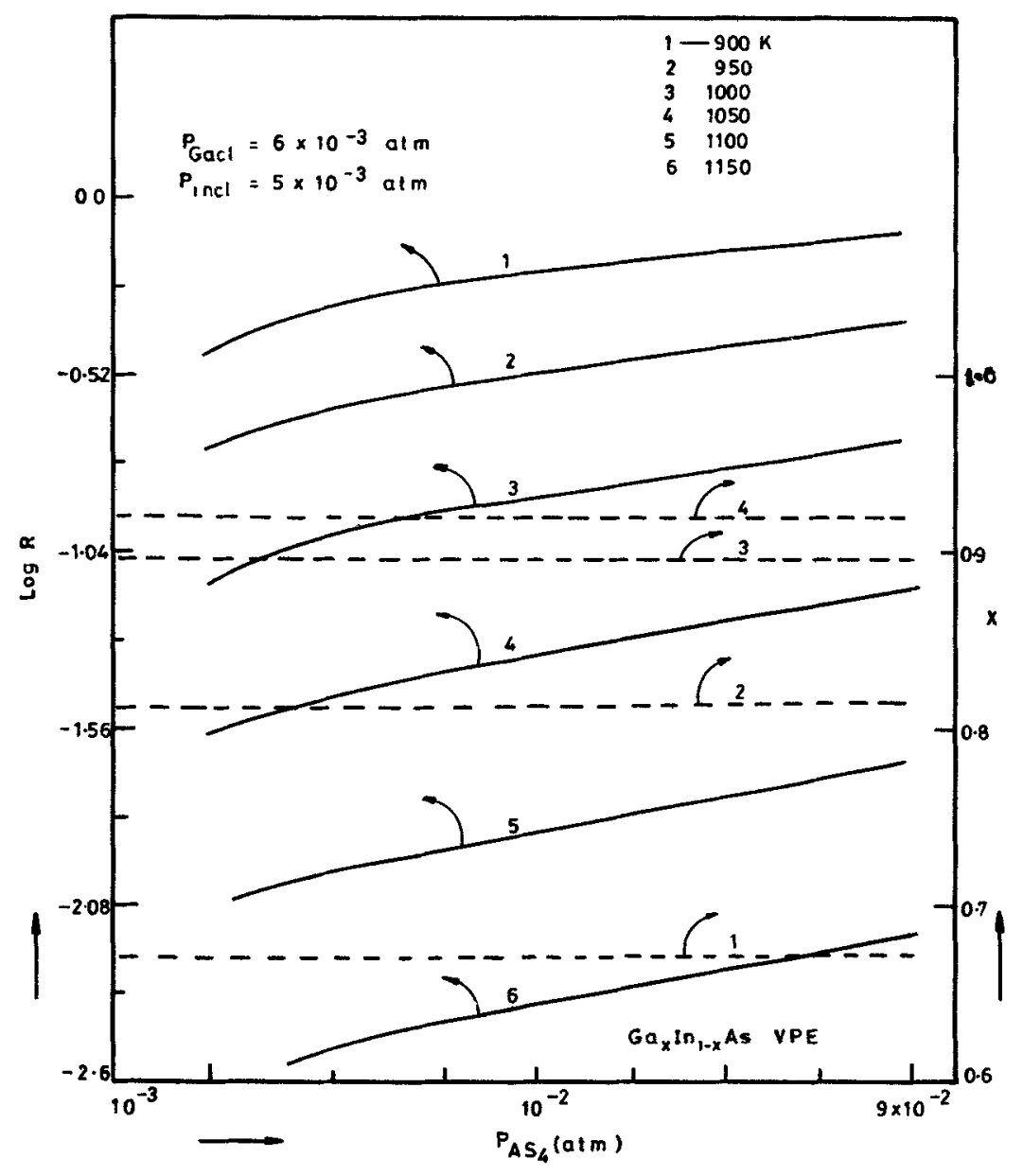

Figure 3. Growth rate $R(-$ ) and mole fraction $x(--)$ of gallium in GaInAs vs partial pressure of $\mathrm{As}_{4}$ at different substrate temperatures and for given values of $P_{\mathrm{GaCl}}$ and $P_{\mathrm{InCl}}$.

may be due to surface reactions and kinetics of the system in both the regions. The effect of arsenic partial pressures on the growth rate and composition has been investigated and the results are presented in figure 3 . The composition of the epitaxial layers at various partial pressures of $\mathrm{As}_{4}$ is nearly constant as predicted and expected from the model. Physically, this is an indication that the relative abundance of $\mathrm{Ga}$ and In remains unchanged, since the deposition temperature and input partial pressures of $\mathrm{GaCl}$ and $\mathrm{InCl}$ are maintained constant throughout the experiment. Another consequence of the model is that the composition of grown layer is no longer specified exclusively by temperature alone. In figure 4, for given input partial pressures of $\mathrm{GaCl}$, $\mathrm{As}_{4}$ and $\mathrm{InCl}\left(=8 \times 10^{-2} \mathrm{~atm}\right)$, the layer composition has been predicted as independent of the deposition temperatures.

In order to illustrate the kinetic processes in more detail, the effect of deposition temperature on the surface coverage has been studied. The results are presented in figure 5 . The uncovered fraction of the surface decreases with decreasing temperature. It is seen that the contribution of the various species present in $\mathrm{Ga}-\mathrm{In}-\mathrm{As}-\mathrm{H}-\mathrm{Cl}$ 

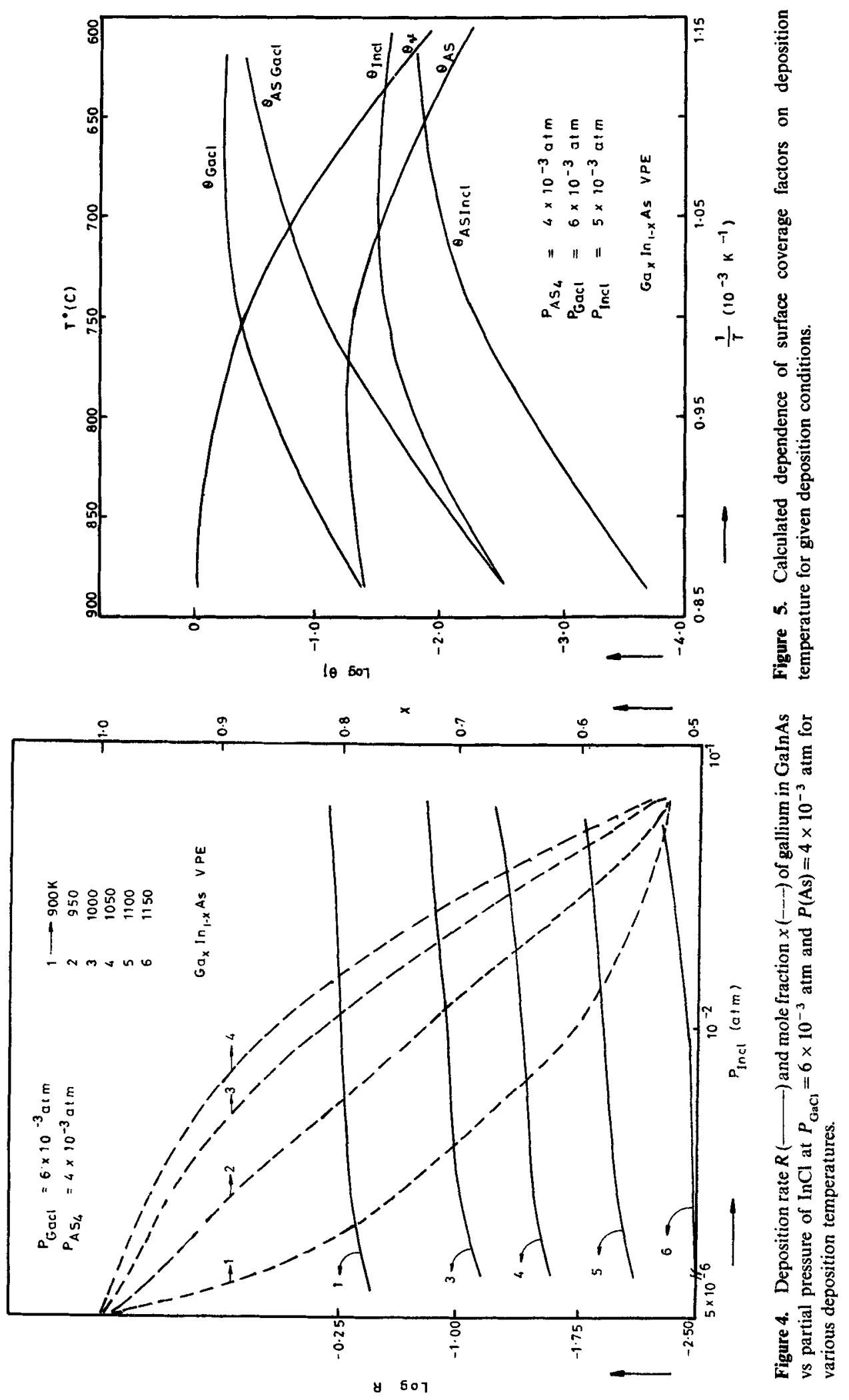


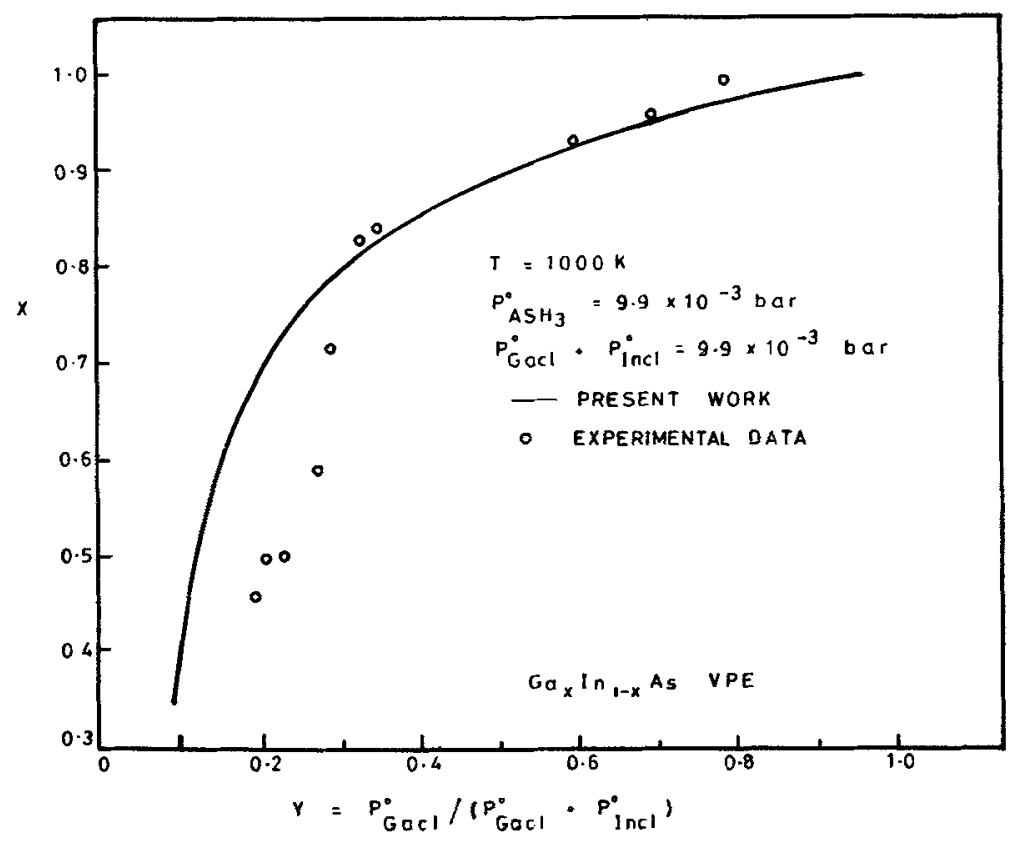

Figure 6. Comparison between present theoretical predictions and experimental results. $(-$ Calculation (present work), and (O) experiment (Jacobs et al 1984).

system to the surface coverage depends on their adsorption/desorption characteristics. In the case of the $\mathrm{GaCl}$ and $\mathrm{InCl}$ adsorption, the dominant adsorbed species seem to be $\mathrm{GaCl}$ and the adsorption of $\mathrm{InCl}$ molecules is less. The surface concentration of $\mathrm{AsGaCl}$ and $\mathrm{AsInCl}$ complexes (whose formation, (11) and (13), constitutes the rate determining step in the growth process) increases with decreasing temperature. Theoretical predictions have been compared with reported experimental results (Jacobs et al 1984) in figure 6.

\section{Conclusion}

A thermodynamic analysis of the $\mathrm{Ga}-\mathrm{In}-\mathrm{As}-\mathrm{H}-\mathrm{Cl}$ system for the vapour-phase epitaxial deposition of GaInAs ternary has been carried out. The effects of various parameters on the growth rate and compositional variation of GaInAs have been discussed based on the kinetic model. The dependence of deposition rate on the composition has been investigated. Theoretical results have been compared with the reported experimental results. Calculated results deviate from reported experimental results in low $P(\operatorname{InCl})$ pressure region. This is due to following the ideal solution theory neglecting the non-ideality parameter in calculations instead of following regular solution model in view of the mathematical complexity. Ternary vapour-phase system includes multicomponent species and also due to nonavailability of typical accurate thermodynamic data, coefficients pertaining to adsorption isotherms, interaction energies ( $\mathrm{InCl}-\mathrm{H}, \mathrm{GaCl}-\mathrm{Cl}, \mathrm{As}-\mathrm{InCl}$ etc.). 


\section{Acknowledgement}

The author thanks Dr R Dhanasekaran and Prof. P Ramasamy for their useful ideas and discussions.

\section{References}

Bachem K H and Heyen M 1984 J. Cryst. Growth 82628

Cadoret R and Cadoret M 1975 J. Cryst. Growth 31142

Chatterjee A K, Faktor M M, Lyons M H and Moss R H 1982 J. Cryst. Growth 56591

Chernov A A and Rusaikin M P 1978 J. Cryst. Growth 4573

Hong J C and Lee H H 1985 J. Electrochem. Soc. 132427

Jacobs K, Simon I, Bugge and Butter E $1984 \mathrm{~J}$. Cryst. Growth 69155

Korec J and Heyen M 1982 J. Cryst. Growth 60297

Lassala F, Porte A, Laporte J L, Pariset C and Cadoret M 1988 Mater. Res. Bull. 231285

Mani V N, Dhanasekaran R and Ramasamy P 1987 Semicond. Sci. Technol. 273

Mani V N, Dhanasekaran R and Ramasamy P 1988 Thin Solid Films 163437

Mani V N, Dhanasekaran R and Ramasamy P 1990 J. Cryst. Growth 99333

Mani V N, Dhanasekaran R and Ramasamy P 1991 J. Appl. Phys. 691399

Nagai H 1979 J. Electrochem. Soc. 1261400

Nishzawa J, Shimaudaki H and Sakuma 1986 J. Electrochem. Soc. 1332567

Oisen G H 1982 in InGaAsP alloy semiconductors (ed.) T P Pearsall (London: John Wiley \& Sons)

Olsen G H and Zamerowski 1979 Prog. Cryst. Char. 2309

Quinlan K P 1987 J. Cryst. Growth 83319 